\title{
Zu viele gemeinsame Patienten? Das kann Ärger geben
}

\begin{abstract}
Nicht immer ist es die KV, die die Zahl der gemeinsamen Patienten in Praxisgemeinschaften überprüft. Wenn es zu viele sind, kann im schlimmsten Fall der Staatsanwalt unangekündigt vor der Praxistür stehen.
\end{abstract}

Wenn Ärzte in Praxisgemeinschaften eine auffallend hohe Zahl gemeinsamer Patienten haben, können sie Besuch vom Staatsanwalt bekommen, ohne dass sich zuvor die Kassenärztliche Vereinigung (KV) bei ihnen gemeldet hätte. „Beim Anfangsverdacht auf einen hohen Schaden will die Staatsanwaltschaft sofort informiert werden“, sagt Dr. Wolfgang-Axel Dryden, Vorstandsvorsitzender der KV Westfalen-Lippe (KVWL), zu Springer Medizin / Ärzte Zeitung. Die KVWL selbst dürfe dann keine Sachaufklärung in den Praxen betreiben. „Wir haben die Weisung, die Fälle umgehend an die Staatsanwaltschaft abzugeben, weil sie die Erfahrung gemacht hat, dass die Praxen sonst zwischenzeitlich Beweismittel vernichten“, berichtet Dryden.

\section{Ärzte sollten penibel trennen}

Praxisgemeinschaften zeichnen sich dadurch aus, dass jeder Praxisinhaber seine eigene Abrechnung macht und selbst für seine Praxis haftet. Gemeinsam nutzen mehrere Ärzte Praxisräume und Praxiseinrichtungen. Praxisgemeinschaften mit identischen Versorgungsbereichen werden in der Plausibilitätsprüfung auffällig, wenn sie mehr als 20 Prozent gemeinsame Patienten haben. Bei versorgungsbereichsübergreifenden Praxen liegt die Grenze bei 30 Prozent. Bis zu einer Überschreitung von 50 bis 60 Prozent darf die KVWL nach Angaben von Dryden dem Grund für die Überschreitungen selbst nachgehen. Ärzte in Praxisgemeinschaften sollten penibel darauf achten, dass die Praxen wirklich getrennt sind, rät der Münsteraner Medizinrechtler Sören Kleinke von der Kanzlei am Ärztehaus. Andernfalls sehen sie sich leicht dem Vorwurf des Gestaltungsmissbrauchs ausgesetzt, sagte er bei einer gemeinsamen Informationsveranstaltung für niedergelassenen Ärzte der Kanzlei und der Deutschen Apothekerund Ärztebank Münster/Bielefeld. Es gibt

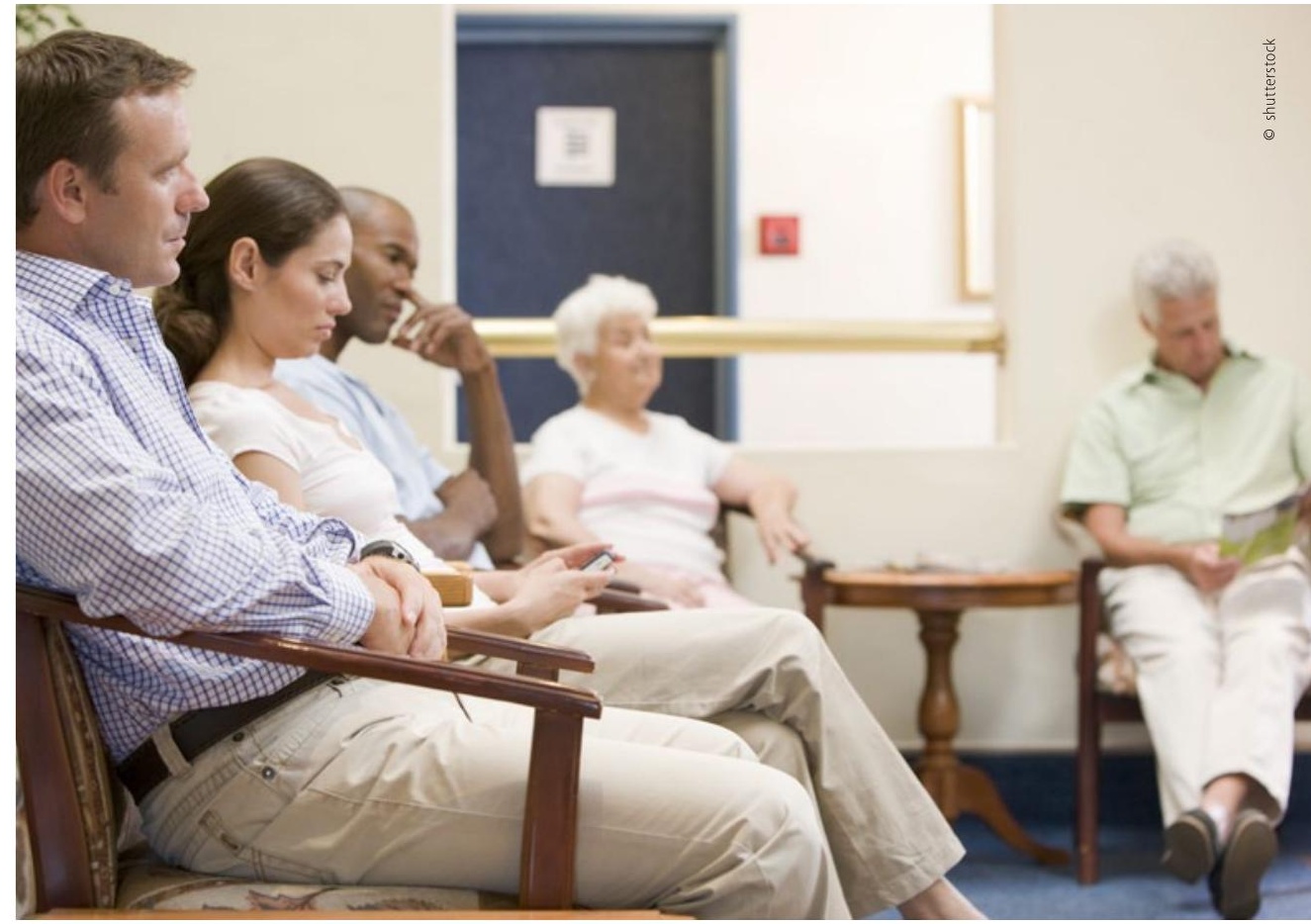

Haben Ärzte in Gemeinschaftspraxen zu viele gemeinsame Patienten, droht ein Besuch der Staatsanwaltschaft.

mehrere Punkte, bei denen die Prüfer hellhörig werden. „Das Gewinnpooling ist ein absolutes No-Go bei Praxisgemeinschaften“, so Kleinke. Innerhalb eines Quartals sei der Arztwechsel von Patienten nur ausnahmsweise zulässig.

\section{So klappt die Verteidigung}

Niedergelassene Ärzte, die durch ihre Zeitprofile auffällig geworden sind, sollten nach Angaben des Juristen verschiedene Verteidigungsmöglichkeiten überprüfen. Ein Aspekt: „Was erbringen sie an delegationsfähigen Leistungen?" So seien für die Körperakupunktur nach EBM-Ziffer 3079120 Minuten vorgesehen. Der Arzt selbst müsse aber nur die Nadeln setzen. Bei Operationen stärken die dokumentierten Schnitt-Naht-Zeiten die Position des Arztes. Auch die be- sonders zeitsparende Praxisorganisation könne die Argumentation stützen. „Das sollte man dann anhand von Praxisgrundrissen aufzeigen", sagte Kleinke. Der Jurist warnte Ärzte davor, sich blind auf die Praxissoftware zu verlassen, wenn sie Plausibilitätsprüfungen vermeiden wollen. Ist die Software fehlerhaft, nutze ihnen das rechtlich nichts. „Es ist Ihre Pflicht als Arzt, sich über die Abrechnungsvoraussetzungen $\mathrm{zu}$ informieren." Auch die pauschale Behauptung, Leistungen schneller als die Kollegen erbringen zu können, sei nicht ausreichend. „Wenn Sie tatsächlich schneller arbeiten können, dann dokumentieren Sie es sauber", empfahl er.

(Ilse Schlingensiepen)

Ärzte Zeitung, 2.3.2013 